\title{
Reverence for the Earth is Animal Rights Ethics
}

\author{
Berta E. Pérez \\ Venezuelan Institute of Scientific \\ Research, Caracas
}

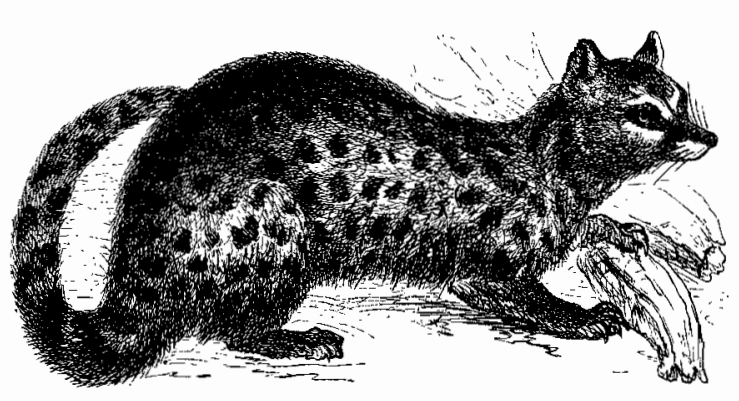

attitudes toward other humans, animals, and the environment are biased by our human self-interest. They claim that these attitudes that we have developed represent parallel relationships that reveal grievous conditions and outcomes. As a result, nuclei of people have emerged throughout history to play an active role, often radical, to rectify what they perceive to be social injustices within their own historical and cultural contexts. The ARM, then, follows the activist tradition against exploitation.

One can say simply that animal rights is the ideology of a social movement comprised by people who believe that animals have intrinsic rights. ${ }^{2}$ Such members claim, however, that these rights are abrogated by the way in which we perceive and treat animals. Therefore, one of their aims is to generate radical sociocultural changes in our usage of these nonhuman animals. In this manner, adherents of animal rights hope to give animals their intrinsic rights and thus end what they see to be a social injustice.

However, animals do not constitute the movement's sole and absolute source of concern, as it often appears to an outsider of the movement. While it is true that advocates of this movement are fighting for the rights and liberation of animals from human dominion, they argue that their preoccupation with the well-being of animals also involves the welfare of humans as well as the whole global ecosystem. The reason is that we are

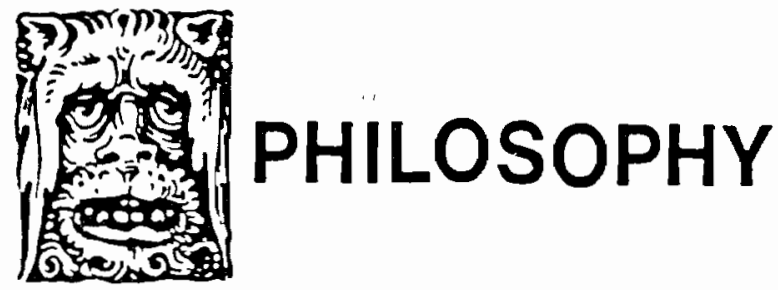


all intertwined and interconnected. Therefore, most supporters of animal rights posit, contrary to what most outsiders of the movement say, that they are not antianthropocentric, nor are they in dissonance with environmental issues. They claim that solutions to human and environmental problems can be realized by achieving the goals set in their work with animals. Although adherents of the movement portray animals as the epitome of vulnerability and victimization, and therefore in need of special protection, I suggest that activists also use this crafted image of animals as one more vehicle for communicating how our current attitudes toward the Earth and its living organisms are slowly heading us into a "silent spring."

To be more exact, the movement's ideology expresses the strains and anxieties that animal rights people feel about science and technology, its anthropocentric and economic biases, and its impact on our ecosystem. Michael W. Fox, for instance, writes:

Science through its technology has been used to dominate and exploit nature, including even inner human nature. It was once thought that science and technology would remedy the social ills of humanity by mastering nature. Instead, they have only compounded and increased those ills. ${ }^{3}$

Most animal rights activists share a feeling that human beings are no longer in control, but rather under the dominion of a high tech "superorganic" in which the laws of "self-interest" and "profit-gain" reign. They claim that people use, abuse, and exploit other living beings as well as the environment. People manipulate other humans to do their work, oblige animals to satisfy their ends at the animal's expense, and exploit other elements of nature for their own gain. Through their continuous application of science and technology in the service of human needs, rather than solving or ameliorating problems of human existence, more problems are encountered and thus, more "solutions" are needed, instead. Adherents of animal rights argue that if we do not change our attitudes, such a situation destroys any sense of ethics and can ultimately lead to an ecological holocaust of all species (plants, animals, and humans) and elements of nature (water, air, rocks, and minerals). Fox aptly states that there are promising signs of change even though our culture is founded on anthropocentric and economic imperatives:

\begin{abstract}
Humane (animal welfare) and conservation movements, working to apply science to the rights of animals and whole ecosystems, have grown and gained strength. This is not just a social revolution but the beginning of an ethical transformation of our culture from utilitarianism to responsible living and a reverence for all life. ${ }^{4}$
\end{abstract}

Most animal rights people of the 20th century share Fox's view. Respect and reverence for all life and the Earth are primordial tenets of their beliefs. The President of Concern and Respect for Animals (CRA), for instance, states: “...you can't segregate any part of our world. And if you care about the welfare of human beings, the welfare of animals, and the welfare of the planet, you can't really separate them at all. They are all intertwined." 5 Although adherents of animal welfare and antivivisection of the 19th century may or may not have had different concerns in comparison to their counterparts of the 20th century, both movements represent a mechanism for change based on their response to the sociocultural conditions of their time.

\section{The Roots of the ARM}

The rise of animal welfare and antivivisection groups in the 19th century best characterizes the beginning of a movement on behalf of animals. While the animal welfare organizations were known for their conventional approach to protect animals from perceived forms of cruelty, the antivivisection groups were by definition proponents of the abolition of surgical cutting of live animals for scientific experiments. Despite their differences, both groups arose in response to the perceived sociocultural injustices of their time, which, in turn, reflected centuries of debate in Western society over the dilemmas of human versus animal and culture versus nature.

The philosophical arguments raised by scholars such as Aristotle, Aquinas, Descartes, Voltaire, Hume, and Darwin, are examples of these dilemmas. Throughout centuries, the basic arguments have been directed toward whether animals have a soul or not and especially, if they are:

1. sentient-aware of and able to experience pleasure and pain,

2. rational-able to reason, and 
3. autonomous beings-capable of making free choices. ${ }^{6}$

The influence of their thinking on these issues still persists to some degree today. But their ideas and beliefs as well as their inquiries and discoveries initiated periods of adjustments and readjustments of our Western cosmology.

Aristotle, for instance, claimed that although humans are the only rational beings, animals have mental capacities that make them sentient creatures. Aquinas, like Aristotle, believed that animals are sentient beings and therefore, subject to cruelty. However, his objection to animal cruelty was based on moral duty to humankind; that is, infliction of pain to animals would ultimately lead to the same treatment of humans. ${ }^{7}$ By contrast, Descartes, writing in the early 17th century, argued against the idea that animals were sentient creatures. He concluded that "animals are machines." His comments were based on his belief that animals are not conscious beings able to experience pleasure and pain, nor are they rational in that they lack a mind and soul, and are unable to speak. By the 18th century, philosophers like Voltaire and Hume not only reemphasized the notion that animals are sentient beings, but also challenged the idea that humans are the only creatures with the capacity to reason. These concepts were furthered supported by Darwin in the 19th century when he postulated his principle of human evolution and therefore, the kinship-implying a difference based on degree rather than kind--between humans and animals.

Their inquiries, however, were not totally directed toward the parallels of human and animal nature. These were also responses aimed at the perceptions and treatment of other humans such as children, women, elderly, mentally retarded, and blacks, and the social conditions and institutions of the time such as slavery, poverty, hunger, disease, and education. It is my contention that human beings' curiosity to learn about their kinship with animals, together with their persistent anthropocentrism and ethnocentrism, create a tension within themselves in how to view and treat living beings. During the 19 th century, this tension was manifested, for instance, in the emergence of animal welfare organizations with more conventional approaches and the rise of splinter groups, such as the Victorian antivivisectionists, with more radical strategies against the established norms of the time.

According to some scholars, there were four trends in the 19 th century responsible for gradually transforming the minds of many people in England and the United States. These were:

1. the rising esteem for science;

2. the acceptance of Darwinian evolution;

3. the concern that any living creature can feel pain; and

4. the era of industrialization and urbanization which created alienation from and nostalgia for nature. ${ }^{8}$ As a result, there was:

1. an increase in animal awareness;

2. a sense of kinship with animals;

3. a configuration of the concept of animal welfare and later, of animal rights; and

4. the popular rallying cries of "going back to nature" and the concept of the "noble savage."

But these trends and outcomes spurred different anxieties and therefore a variety of responses: there were those people in support of animal utilization and with no stated concern for animal welfare, those in favor of protecting animals from general cruelty, and those against animal vivisection. ${ }^{10}$

The historical accumulation of our Western dilemmas and sociocultural conditions gave rise not only to an awareness of the perception and treatment of other humans, but also of animals. In essence, many people viewed the issues to be similar and the outcomes to be parallel. While there were certain groups working against slavery and child labor, for instance, there were others fighting against animal vivisection and for the prevention of cruelty to animals. Most important, there were people who participated in both human and animal issues. But the concern for animals became evident through the establishment of traditional humane societies and the emergence of antivivisectionist groups, both of which have their parallels in the 20th century. Sperling describes their relationship as follows:

In the nineteenth century, as now, the former [traditional humane groups] represent a traditional reform-oriented movement, like the great humanitarian reform movements of the nineteenth that abolished slavery and child labor. Both antivivisection and animal rights, in contrast, are radical attempts to realign aspects of the human relationship to nature. Nineteenth-century antivivisectionists felt themselves to be completely separate from, and often at odds with, the mainstream humane movement. Similarly, the modern animal rights 
advocates consider themselves to be distinctly different from the local human society. ${ }^{11}$

Sperling's comments point out that the separation between traditional reforms and radical departures are not different in the 20 th century. However, one key difference between then and now is that the animal rights movement of the 20 th century has expanded its ideology by radically embarking to create a "new Eden"- - or a harmonious and balanced integration of nature and culture as well as of human and animal.

Lester Y. Ichinose, Science Director for the National Anti-Vivisection Society, says that the roots of the contemporary animal rights movement can be traced to the environmental movement and particularly, to Rachel Carson's book, Silent Spring. ${ }^{12}$ Carson, for instance, states:

THE HISTORY OF LIFE on earth has been a history of interaction between living things and their surroundings. To a large extent, the physical form and the habits of the earth's vegetation and its animal life have been molded by the environment. Considering the whole span of earthly time, the opposite effect, in which life actually modifies its surroundings, has been relatively slight. Only within the moment of time represented by the present century has one species-manacquired significant power to alter the nature of his world. ${ }^{13}$

Most adherents of animal rights agree with Carson's statement when they say that the harmonious and balanced state of the Earth was altered when humans began to effect radical changes in the ecosystem. They argue that everything found on Earth has a place, a purpose, and an interconnection that should exist with very little or, perhaps, without human interference in accordance to the laws of nature.

\section{Peter Singer and the ARM}

Most animal rights people make the claim that Peter Singer's book, Animal Liberation, published in 1975, was a major turning point for the ARM. Singer, an Australian utilitarian philosopher, provides a cohesive moral and philosophical perspective on the rights and liberation of animals, and this book has come to be accepted as the movement's bible. In essence, he is the first person to popularize and synthesize the concepts of "speciesism," "equal consideration," and "moral rights."14

Singer argues that unique human faculties such as the abilities to reason and to talk, have made most people speciesists; that is, human beings' self interest takes precedent over the interest of other species. Animals are not only considered inferior creatures, but also they do not have the necessary sentient capacity that would include them in the realms of moral and legal rights. In essence, Descartes' views on animals still prevail in our society in one degree or another. Without questioning our perceptions of and attitudes toward animals, they are often used as:

1. sources of food;

2. means to provide energy or power;

3. commodities for vanity, comfort, and status;

4. subjects for experimental research;

5. forms for entertainment; and

6. dependent companions kept to fulfill our social and emotional needs.

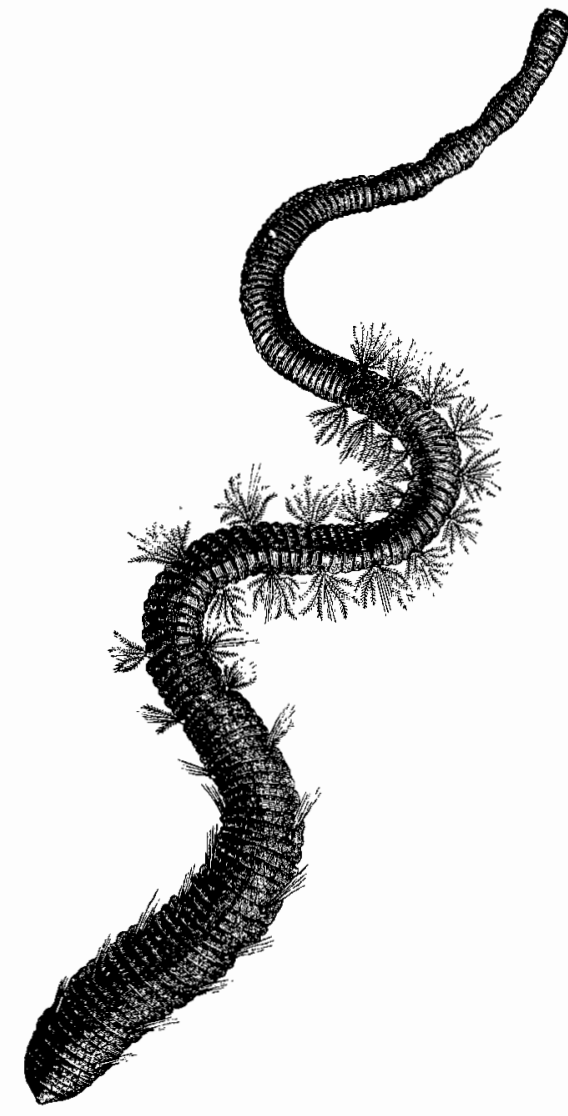


Singer posits, however, that some humans such as infants or the mentally retarded, lack certain unique human faculties. As a result, these people share attributes of animals. Yet, society protects this class of humans by moral and legal mechanisms. Singer refers to this type of perception and attitude as speciesism, which he equates with racism and sexism. ${ }^{15}$

He uses the argument against speciesism to introduce the concepts of equal consideration and moral rights. He states, "The basic principle of equality does not require equal or identical treatment; it requires equal consideration. Equal consideration for different beings may lead to different treatment and different rights."16 Singer argues, for instance, that it becomes meaningless to address a man's right to have an abortion within the debate of gender equality, just as it is meaningless to speak of a dog's right to vote in a political system. ${ }^{17}$ These two cases are intrinsically impossible. Yet, Singer infers that the rights of those beings who have interests within their own intrinsic nature ought to be acknowledged. In his promulgation of animal rights and liberation, he follows Jeremy Bentham, a British utilitarian philosopher, from whom he quotes, "The question is not, Can they reason? nor Can they talk? but, Can they suffer?"18 Singer postulates that if it is wrong to use defective humans, then it must be equally wrong to use animals. He concludes that animals have moral and legal rights based on the principle of equality, or equal consideration of interests, because they are also sentient beings. ${ }^{19}$

Singer's moral and philosophical foundation continues to fortify the ARM's emerging ideology. ${ }^{20}$ He provides the ARM with ideological links to other social causes and supplies the rhetoric for its cause. Most animal rights people equate the concept of speciesism with racism and sexism, which they view as one more form of oppression and exploitation that exists in our society.

Most adherents of the movement perceive the status quo or opposition to be the patriarchal, oppressive, and profit-motivaled system; or as they often express it: "the White, male system." The many forms of oppression and kinds of exploitation of humans, animals, and the environment, are seen as realistic examples of the actions taken by the status quo-actions that will ultimately lead to the destruction of the Earth's ecosystem. These images represent persistent "evildoing," especially of Western societies which hold ingrained conceptual dichotomies such as oppressor and oppressed, exploiter and exploited, and victimizer and victim. Each form of oppression or exploitation is viewed by most animal rights people as continuances and symbolic expressions of each other. For most advocates, animals are not just symbols of other types of oppression and exploitation, they are also the epitome of vulnerability as sentient beings. Because animals "cannot speak for themselves," participants of this movement have taken the initiative "to speak on their behalf." This is one motto that most animal rights activists use in their fight to abolish speciesism. In their view, people can fight for their own rights because they can speak for themselves, whereas animals cannot. Animal rights people claim that Western logical reasoning denies animals their rights simply because they cannot speak: where there is no speech, there is no voice; where there is no voice, there is no choice; where there is no choice, there are no rights.

In their defense of animals, religion is included to clarify that the statement in Genesis that "God gave us dominion over all living creatures," is a mistranslation of the Hebrew, and that stewardship is the correct gloss; animals are not people's property but sentient beings to be cared for by humans. Therefore, advocates of animal rights see that animal existence, in terms of their moral and legal rights, is dependent upon the movement's beliefs and actions. But they claim that the liberation of animals will ultimately affect the conditions of humanity. As a result, they have another motto: "Animal liberation is human liberation, too" which also implies "the dawning of a new Eden." Fox elaborates:

Human salvation is wholly dependent upon the liberation of nature from our selfish treatment and on bumane consideration. Human liberation will begin when we understand that our evolution and fulfillment are contingent on the recognition of animal rights and on a compassionate and responsible stewardship of nature. The dawning of a new Eden is to come. ${ }^{21}$

Activists of the ARM admit that humans cannot return to the "Garden of Eden," regardless of whether it is a reality or a myth and whether it connotes a harmonious integration of humans, animals, and their common habitat. Despite this recognition, they continue to strive for a similar Paradise, the "new Eden." The "new Eden" paradigm provides the detailed intricacies of a perfect 
world or Utopia, without inconsistencies and contradictions, and it is correlated with the practice of veganism as the ultimate ethic of reverence for all life. ${ }^{22}$

In addition to the "new Eden," advocates of the movement also offer another paradigm, a "better world." Besides being associated with vegetarianism as the penultimate concern for all life, the "better world" is a more realistic and pragmatic paradigm in the sense that compromises are perceived as a more attainable strategy. ${ }^{23}$ It is based on the idea that animal utilization is reduced as a right step in the direction of ultimate abolition, and soil, water, and plants are conserved. This world, however, would still contain inconsistencies in that there is some human interference with the ecosystem. If either paradigm is not taken as a course of action, animal rights people argue that the future will be chaotic and self-destructive.

The concept of "animal rights" may have been hidden before Singer. But, he certainly opened the doors for the participants of the movement to profess animal rights and liberation, and to become active agents for their beliefs. Most animal rights advocates explain that prior to the publication of Singer's book, the usage of "rights" in reference to animals was considered too avant-garde or radical, and therefore it was seldom mentioned in their cause. Today, its use has increased to the same frequency of usage as the term "animal welfare," which may be indicative of the movement's rapid growth.

\section{Current Patterns of the ARM}

The 20th century is not necessarily a new era but rather a historical continuation of human concerns about social, animal, and environmental issues. Additional ramifications and extensions of human use, abuse, and exploitation of other humans as well as animals and the environment are still prevalent in this period. The emergence of numerous social movements such as civil rights, women's liberation, the environmental movement, and the animal rights movement, are examples of the decisive role that certain people take in order to put an end to the present forms of oppression by implementing radical changes in the status quo. Although each movement represents its own cause, they are actually interrelated on a broader ideological level; that is, the sacredness of all life and the environment. Jeremy Rifkin, President of the Foundation on Economic Trends in Washington, D.C., elaborates on this interrelationship in an interview with an animal rights magazine, The Animals' Agenda:

The animal rights movement is not only an activist movement. It is an attempt to change the consciousness of the culture.... There is a whole new group of constituencies emerging: animal rights, eco-feminism, the bio-regional movements, worker self-management movements, the disarmament community, organic agriculturists and the preventive health people. In one way or another, all these individuals are trying to resacralize life and they are flying in the face of the prevailing world view.... Each is involved in its own set of issues, but they all represent a broader philosophical focus which says that life is more than just functionality, more than just productivity, more than just expediency, utility and efficiency. ${ }^{24}$

The ARM emerged during the 1970's with the appearance of numerous grass roots animal rights organizations. ${ }^{25}$ Their presence in the United States was increasingly felt after the mid-seventies, especially with the advent of Animal Liberation. Singer's perspective gives the ARM its first unifying themes that delineate the movement and the ultimate goals of its people. Some of these themes are:

1. anti-speciesism;

2. equal consideration of interests;

3 . moral and legal rights of animals;

4. animal and human liberation;

5. vegetarianism and veganism;

6. respect for the Earth and all life; and

7. harmony and balance in the new Eden.

Not only do these themes represent the movement's web-one that ensures the survival of the Earth's ecosystem and its living organisms; these also furnish the animal rights people with unifying links to their emerging ideology. Animal rights people agree that these themes represent the ultimate achievements and bring these together in their advocacy of a social cause.

It is perhaps for these reasons that Singer's book has gained so much popularity among animal rights advocates. His arguments connect a historical past to the present and furnish a transition from the past into the future. He not only makes analogies between speciesism and racism or sexism, but also invites the readers to question those concepts in their treatment of 
humans and animals. It is this cohesive perspective that he has given to the movement.

Unlike the animal welfare organizations, which deals with animal issues deemed acceptable by the status quo such as preservation of wildlife or taking care of strays dogs and cats, the animal rights groups are known primarily for their advocacy of animal rights and animal liberation. Yet, this does not imply that most of these animal rights groups refute the idea of animal welfare, nor do they only practice animal rights and liberation ideologies. Cooperation is sometimes stressed between the animal rights groups and the animal welfare organizations. Demonstrations at the National Institute of Health against its funding of primate experimental research and the support that animal rights groups give animal welfare organizations with respect to legislation are but two examples.

Despite the fact that Singer inspires the movement with some unifying themes, ideological diversity among advocates of animal rights is also a reality. They recognize that as individuals and as groups, their ideology is diverse. They vary in their foci, interests, strategies, goals, and life-styles.

This diversity is manifested in the following ways: the first variant is that the movement embraces animal welfare, animal rights, and animal liberation in one degree or another. Depending on the perspective adopted by animal rights organizations, these can be ranged along a continuum based on their strategies and goals or as Gerlach and Hine call "goals-means orientation." 26 Animal rights groups with an animal welfare perspective, such as P.A.L. Inc. (The Minnesota Pet Owners Association), are on the conservative end; those with an animal liberation view, such as Animal Liberation Front (ALF), are on the radical one; and those with an animal rights focus, such as Concern and Respect for Animals (CRA), are moderate and somewhere between the two.

Animal advocates with a conservative stand work with animal issues that are acceptable to the public. They also prefer to use more acceptable approaches within the legal system and believe that a more gradual and legal approach will eventually secure the well-being of animals. Those with a radical position address issues such as factory farming and animal experimentation in a violent direct action manner. Although they may support legislation or participate in nonviolent direct action, they purport that break-ins of animal facilities is the only method that will bring about the quick liberation of animals. Those with a moderate approach also raise crucial animal issues but through the use of combined approaches such as legislation, education, and nonviolent direct action (boycotts, protests, and civil disobedience). Although they do not condone violent direct action, they certainly praise the accomplishments of those who do practice that approach.

The second variant is abolition versus reduction of animal practices such as factory farming, experimentation, and entertainment. While some groups believe in the abolition of all or some utilization of animals, others prefer reduction. A similar situation occurs in the efficacy of either beliefs; that is, some advocates proclaim reduction to be a more practical route to attain gains, rather than to demand immediate abolition which is perceived as likely to be rejected by the status quo. Third, there are differences of interests in animal issues, such as actions against veal production, psychological experimentation, or trapping, based on a weigh scale of what they perceive to range from the most heinous to the most innocuous. Groups may embrace many or only one animal issue. While CRA, for instance, fights against factory farming, experimentation, and entertainment, Friends of Animals and the Environment (FATE) is concerned with wildlife issues such as hunting and trapping. P.A.L. Inc., as another example, is primarily interested in decreasing the pet population through a campaign of neutering and spaying. Fourth, the strategies that advocates employ to initiate sociocultural change can range from legislative procedures, education, nonviolent demonstrations, to violent acts. While ALF uses violent demonstrations, CRA follows the first three strategies mentioned above. Finally, the majority of the advocates practice either vegetarianism or veganism; those on the conservative side may practice neither. But together, animal rights activists incorporate in their fight every aspect they view as animal use, abuse, and exploitation in society.

This diversity need not imply disunity or dissonances. A combination of seemingly incongruous elements does not alter their attempts to attain ideological unity. In fact, the diversity of this movement provides the dynamic necessary for its continuation and growth. They emphasize the few shared fundamental beliefs and values and form situational alliances through compromises. The alliances reveal the diversity among the supporters and also demonstrate their willingness to act in concert for a specific cause or concern. 
In essence, diversity increases recruitment, ensures continued membership, enhances commitment, and assures effectiveness by providing alternative ideological variants under a unified association of the movement's basic principles. Members come together as individuals or groups when they meet common goals such as the banning of the steel jaw trap; or they break apart when they do not agree on issues such as the repeal versus prohibition of "pound seizure" law. ${ }^{27}$ These separations do not connote that they are no longer working within the ideological matrix of the ARM. They simply operate under different premises but argue that the accomplishments achieved are far more important. The accomplishments made ultimately mean being a step closer in realizing the movement's unifying themes.

\section{Discussion and Conclusion}

The ARM has become familiar to most outsiders as a result of its day-to-day exposure, especially in the media. The issues that animal rights people raise and the actions that they take not only occur in one's own backyard, but are also prevalent worldwide. ${ }^{28}$ Outsiders to the movement, however, are often exposed to: rhetorics like "animal rights" or "animal liberation," statements such as "it is morally wrong to eat meat and animal by-products" or "animal experimentation is morally wrong and ought to be banned," and images of more violent scenarios such as break-ins or civil disobediences at animal related facilities.

Seldom is the public aware of other messages within the movement's ideology that are expressed by advocates of animals. Some of these hidden or obscured messages are:

1. besides the unequal distribution and high prices of food, there is hunger in the world because a major proportion of grains grown is being used to feed animals kept in factories;

2. the wilderness is being destroyed and a number of animal species are being brought close to extinction in the name of economic gain obtained through an increment of urbanization, industrialization, and commercial agriculture among others;

3. environmental pollution is increasing in order to maintain an infrastructure designed to produce economic gain, such as the use of pesticides in agriculture and drugs and chemicals in food, as well as the release of chemical waste by oil and energy companies and animal waste by factory farms into the sewer systems or directly into our waters;

4. more and new human as well as animal diseases are proliferating as a result of our polluted environment and living conditions; and

5. human self-interest and profit-gain are slowly destroying all living organisms and their surroundings.

These messages are, perhaps, hidden because we make an effort not to hear them, nor to see them in real scenarios; or maybe they become obscured as adherents of the movement often place an emphasis on animal rights and liberation. Anne Sutherland, an anthropologist, wrote an article in a Minnesota newspaper, where she claims that "much 'animal rights' activism amounts to anti-humanism" because animal rights supporters put the mutual survival of humans and animals at stake. ${ }^{29}$ While many people, like Sutherland, posit that much animal rights activism amounts to anti-humanism, most animal rights people would argue otherwise. They say that their humanism begins with animals.

A close examination of the movement reveals that most animal rights people are not aloof, nor oblivious to human and environmental conditions. Sperling, for instance, states that, "For many [adherents of the movement] today, there is a deep tie between aspects of inner and outer nature; the body and the ecosystem and what happens in the environment may have drastic repercussions within the body." 30 Thus, they believe that their work on behalf of animals contributes toward solving many social and environmental problems. Animal rights supporters purport that if we live a vegetarian or vegan life-style, practice preventive medicine, and maintain a healthy and clean environment, we will lead a life that is in harmony and balance with nature. Although adherents of the movement believe that animals do have intrinsic rights, I posit that these activists perceive the endowment of rights to animals as an absolute necessity in order to assure the well-being of animals and ultimately guarantee human compliance with the ethic of reverence for the whole Earth and all forms of life.

However, the reality is that we feel threatened by the movement and its members. When our constructed Western boundaries such as those between nature and culture, and between human and animal, are crossed, ambiguities do arise that make us experience tension and anxiety. The endowment of anthropomorphisin and 
rights to animals by animal rights people crosses our constructed Western boundaries and, in turn, creates moral and philosophical dilemmas such as where to draw the line(s) between nonhuman mammals and humans, other animal species, plants, or ecosystems. ${ }^{31}$

Our Western tradition has often maintained an arbitrary, but sharp division between nature and culture as well as between humans and animals. Even within culture, humans have also kept an arbitrary but defined separation between those who are perceived as being privileged and those who are not so privileged (children, women, minorities, and the insane). Some of the factors used to make these distinctions are the capacity for sentience, speech, rationality, autonomy, and culture. Throughout history, these faculties have been assigned as unique human characteristics that have separated culture from nature and humans from animals. Yet, these have also been utilized to create boundaries between the privileged and not so privileged human beings such as the mentally retarded who may lack the capacity for speech, rationality, and autonomy. But even though the not so privileged are often metaphorically associated with animals through the imputation of animal-like qualities, these human beings are seldom seen metonymically equal to animals; that is, they are not unfitted of moral and legal protection.

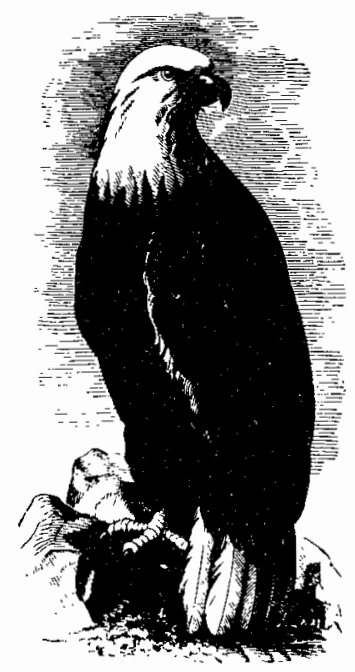

Although Gaylin argues that humanity is measured, in part, by the human treatment of animals, he posits that animal rights advocates undermine the special nature of being human by constantly emphasizing similarities between humans and animals; thus, animal rights supporters reduce the distance between human and animal nature. He says, "The purpose of the people in this movement is not to diminish Homo sapiens but to protect the beast. They do so by elevating animals, often endowing them anthropomorphically with features the animals do not possess." ${ }^{32}$ Most people do anthropomorphize animals, especially pets. ${ }^{33}$ But in agreement with Gaylin, animal rights advocates do use anthropomorphism to elevate animals onto a human-like status. This elevation, however, is increased even more so when animals are endowed with moral and legal rights in order to attain their liberation from human dominion.

One aspect is for humans to have reverence for all living organisms and their surroundings, but another is to endow animals with moral and legal rights. So the elevation of animals onto a human-like status subject the established boundaries and interrelationships of animal and human, nature and culture, and nature and nurture to a more intensive scrutiny. Although these interrelationships with or without boundaries are cultural constructs that deserve serious attention, the advocacy that animals are entitled to moral and legal rights raises important questions. Some of these are: if animals deserve equal moral and legal considerations as humans, then what is the nature of Homo sapiens and that of animals? Where does the concept of culture come in and what role does it play? Does the concept of culture play a significant role in distinguishing humans from animals? Is culture just an illusionary construct to intentionally augment the distance between humans and animals or ecosystems? And is the endowment of rights to animals necessary in order to create a "new Eden" or a "better world" based on reverence or respect for the Earth?

Our feelings of tension and anxiety that arise when our boundaries are crossed, are often alleviated by mechanisms created within our own culture. Sperling states that:

...the distinction between humanity and the world of nature is at the heart of human culture; culture defines that distinction and ritualizes anxieties when boundaries between humans 
and nature are crossed. Thus, some rites of passage have been interpreted as relieving human anxieties at crucial boundaries between culture and nature encountered during the human life cycle. ${ }^{34}$

One of the mechanisms that the larger society has utilized against the movement and its people is the portrayal and classification according to stereotype images. Animal rights people argue that the terms such as "little old ladies in white tennis shoes," "Bambi lovers," "Bambi syndrome," "animal lovers," "human haters," and "terrorists," applied to them are an attempt to emphasize or even increase their alienation from the larger society. They claim that society is not ready to adopt the movement's ideology and thus, put it into practice. However, animal rights supporters continue to strive for an image that negates these stereotypes, especially when they are in confrontation with the opposition. In their endeavor to protect a more positive image, they repress highly overt emotions so as to avoid being classified as "hysterical or irrational," and conceal any inconsistencies or contradictions in their own lifestyle in order to escape from being called "hypocrites."

Adherents of the movement state that they do not have to love animals to believe that animals ought to have freedom and respect from humans. They do not see themselves as human haters, either, because they do not disregard human causes. Instead, they believe that humans have other humans to fight for their own cause and, besides, humans can speak for themselves. Animals have no one and they cannot speak. ${ }^{35}$ As one member of CRA expresses, "Sometimes I wonder what it would be like if a trapper was going to get his catch and was still alive; and the fox looked up and said, 'Please!' in this human voice." 36

Another threatening situation is that through the adoption and practice of the movement's ideology, human beings will have to renounce their values of "self interest" and "profit-gain" as long as these interfere with the well-being of the whole global ecosystem. Fox, for instance, elaborates:

...the systems which serve us must be better controlled for the greater good of all humanity in harmony with the rest of the world....selfserving interests must not conflict with the interests of all life on earth. When they do, science and technology should help eliminate

\begin{abstract}
the conflicts between man and nature. Man must be held accountable for his actions in a much broader framework than ever before, embracing humane ethics, respect for the rights of nonhuman life, and awareness of the ecological principles by which all individuals, societies, and industries must abide....he must be a cocreator, harmonizing ethically, socially, spiritually, and ecologically. This is an essential evolutionary step, part of becoming civilized and fully human. We work in harmony with nature-to steward, conserve, and, wherever possible, preserve the primal state. Nature can be used, even reshaped, to sustain human interests, provided we respect and abide by its laws and rights. We can embrace nature and its Potentials, but we may not destroy. ${ }^{37}$
\end{abstract}

This view is neither anti-anthropocentric, nor in dissonance with environmental principles. Moreover, it is not considered to be either oppressive or exploitive toward other human beings, animals, and the environment. Instead, this view demands reverence for the Earth based on human actions that would ultimately bring the idea that "animal liberation is human and environmental liberation, too" into reality.

The idea that humans, animals, and the environment are woven into a single fabric is no longer strange. However, animal rights people are judged as radical dissenters by society. Their degree of concern and views about the well-being of the Earth's species and their environment is often considered extreme. But similarly, the established views on the interrelationship of humananimal-environment can also be considered extreme by others, such as animal rights activists.

The ARM, like other social movements, continues the tradition to fight against perceived social injustices. But unlike other social movements, the ARM is, perhaps, the most holistic. It encompasses human, animal, and environmental issues with global implications and ramifications. The ARM has become a global group, addressing global issues, and is no longer limited to a sacred cow or a sacred dog. It argues that the "sanctity of all animals" is necessary for mutual survival. Philosophically, it confirms that being good to animals does not justify one's own humanity: humans must integrate into the ecosystem and animals must be integrated into human culture in order to reach cultural and ecological harmony. 


\section{Notes}

${ }^{1}$ I did my fieldwork with a little-known Midwestern animal rights organization, which I name Concern and Respect for Animals (CRA) in order to protect its identity. In addition, I contacted other animal rights groups at the national and international level in order to gain an overall view of the movement at a larger scale. The formal and informal interviews that I carried out with participants of these organizations, and especially with those members of CRA, reveal their preoccupation with our present state as human beings as well as of our environment. This paper is based on my analysis of the literature on animal rights as well as of the data gathered in fieldwork. My intention in this article is to discuss how the movement perceives itself, rather than to enter into the rhetorics or philosophical discussions with moral humanists or environmental ethicists; either focus requires special attention in itself and the length of this article does not permit it.

${ }^{2}$ My fieldwork experience with animal rights people led me to conclude that they do not have a black and white definition for "animal rights" or "animal have rights." But what is meant by it has its foundation in the writings of Benthan (Introduction to the Principles of Morals and Legislation. New York: Hafner Publishing Co., 1948) and Singer (Animal Liberation. A New Ethics for Our Treatment of Animals. New York: Avon Books, 1975). They claim that animals have intrinsic rights-not to be tortured or killed, because they are also sentient beings; and as sentient beings, they require equal consideration based on their own interestsnot to experience emotional suffering or physical pain.

${ }^{3}$ Michael W. Fox, Returning to Eden. Animal Rights and Human Responsibility (Malabar, Florida: Robert E. Krieger Publishing Company, 1986), pp. 136-137.

4 Ibid., p. 215.

${ }^{5}$ Personal communication, 19 December 1986

${ }^{6}$ Tom Regan, "Introduction" in Tom Regan and Peter Singer, eds., Animal Rights and Human Obligations (Englewood Cliffs, New Jersey: Prentice-Hall, Inc., 1976), p. 8.

? Animal rights advocates do not agree with Aquinas' statement because they claim that people cannot use animals as an excuse toward their own salvation; salvation is only found when humans carry out their moral obligations to care for the whole ecosystem without human motives.

${ }^{8}$ James Tumer, Reckoning with the Beast (Baltimore: The Johns Hopkins University Press, 1980), p. xi; Yi-Fu Tuan, Dorninance and Affection. The Making of Pets (New Haven: Yale University Press, 1984).

${ }^{9}$ For additional discussion see Michael W. Fox, Between Animal and Man (New York: Coward, McCann \& Geoghegan, Inc., 1976); Stephen R. Kellert and Meriam 0. Westervelt,
"Historical Trends in American Animal Use and Perception," in Transactions of the 47th North American Wildlife and National Resources Conference (Washington, D.C.: Wildlife Management Institute, 1982); Henry M. Parrish, "AnimalMan Relationships in Today's Environment," American Journal of Public Health 63, no. 3 (1973): 199-200; Charles Phineas, "Household Pets and Urban Alienation," Journal of Social History 7 (1974): 338-343; Yi-Fu Tuan, Dominance and Affection. The Making of Pets (New Haven: Yale University Press, 1984); and James Turner, Reckoning with the Beast (Baltimore: The Johns Hopkins University Press, 1980).

${ }^{10}$ Because England was more industrialized and urbanized than the United States in the 19th century, British people experienced a more intense period of animal welfare regulations and radical activism from antivivisectionists groups.

11 Susan Sperling, Animal Liberators. Research and Morality (Berkeley: University of Califomia Press, 1988) pp. 27-28.

${ }^{12}$ Personal communication, 8 August 1987.

${ }^{13}$ Rachel Carson, Silent Spring (New York: Ballantine Books, 1962), p. 16.

${ }^{14}$ Peter Singer owes the term "speciesism" to philosopher Richard Ryder who coined the word. Ryder was also the first person to use the term "animal rights" in his book, Victims of Science (London: Davis-Poynter, 1975).

${ }^{15}$ Peter Singer, Animal Liberation. A New Ethics for Our Treatment of Animals (New York: Avon Books, 1975), p. 7.

$$
\begin{aligned}
& { }^{16} \text { Ibid., p. } 3 . \\
& { }^{17} \text { Ibid., p. } 2 . \\
& { }^{18} \text { Ibid., p. } 8 .
\end{aligned}
$$

${ }^{19}$ Jeremy Bentham was one of a few philosophers to realize that the principle of equal consideration of interest in some form or other, applies to members of other species as well. The quote given in the text can be found in his book, Introduction to the Principles of Morals and Legislation (New York: Hafner Publishing Co., 1948), chapter XVII, Sec. 1, p. 311n.

${ }^{20}$ Although I did not encounter any arguments made against Singer's moral and philosophical perspective by the animal rights people who I interviewed, Singer has been highly criticized by many scholars. These criticisms are based on his utilitarian principles, his use of the concept "speciesism" in relation to "racism," and his view, whether implied by Singer or misread by others, that instead of nonhuman animals, retarded people, for instance, could be utilized in medical experiments if their use brings the largest possible balance of pleasure over pain. It is my assumption, based on my fieldwork, that the movement's ideology represents a combination of: certain characteristics adopted 
from the perspectives given by people such as Peter Singer in Animal Liberation. and Tom Regan in The Case for Animal Rights (Berkeley: University of California Press, 1983), interpretations of these views, and incorporation or modification of new information: and the outcome of this combination depends on how each animal rights organization decides to build its own ideology accordingly to the premises of the movement.

${ }^{21}$ Michael W. Fox, Returning to Eden. Animal Rights and Human Responsibility, p. xiv.

${ }^{22}$ Most animal rights people claim that veganism implies ethics rather than diet. Those who consider themselves vegans live an animal-free life-style that shuns meat, leather. honey, and silk.

${ }^{23}$ Vegetarianism implies diet and perhaps, a step closer to living an ethical life. Those who consider themselves vegetarians live an almost animal-free life-style that would include, in the most extreme cases, people who would eat cheese and yogurt but would not wear leather or wool; or would not eat any animal by-products but would still wear leather or silk.

${ }^{24}$ David Macauley, "Why Jeremy Rifkin Is Saying 'No' to the Age of Progress." The Animals' Agenda vii, no. 2 (1987), p. 41.

25 For more detailed information on the structure of the animal rights movement, refer to Berta E. Perez, Ideology of the Animal Rights Movement (Minneapolis, Minnesota: University Microfilms, 1990)

${ }^{26}$ Luther P. Gerlach and Virginia H. Hine, People, Power, Change: Movements of Social Transfomation (Indianapolis: The Bobbs-Merrill Company, Inc., 1970).

27 The "pound seizure" law allows animal pounds to give away unwanted animals to medical research institutions after the claim period for pet owners to retrieve their own animals has expired.

${ }^{28}$ Some examples of animal rights activism that occurred at the local, national, and international level during the time of my research are:

1. protests against animal experimentation at the University of Minnesota;

2. protests against the selling of furs at Schlamp's and Dayton's, which are two major department stores in Minnesota;

3. a bomb planted in the United States Surgical Corporation. Connecticut by an animal rights activist;

4. the Massachusetts farm animals bill of rights, which was vetoed;

5. the Swedish farm animals bill of rights. which was passed; and

6. international protests against whale hunting practiced by countries like Japan and Iceland.
29 Anne Sutherland, "much 'animal rights' activism amounts to anti-humanism," Saint Paul Pioneer Press (23 June 1991), p. 15A

${ }^{30}$ Susan Sperling, Animal Liberators. Research and Morality, p. 153

${ }^{31}$ Numerous scholarly works have been written on animal rights as well as on human and animal nature. One main criticism against animal rights is that the movement is antibumanism. Similarly, environmental ethics claims that animal rights is not environmental in its perspective because it does not consider the biotic community. For additional discussion about animal rights versus environmental ethics, refer to such sources as the quarterly journal, Environmental Ethics, and the book, The Animal Rights/Environmental Ethics Debate. The Environmental Perspective, ed. Eugene C. Hargrove (Albany, New York: State University of New York, 1992).

32 Willard Gaylin, Adam and Eve and Pinocchio (New York: Viking Penguin, 1990), p. 11.

33 See Christopher Manes, "Nature and Silence," Environmental Ethics 14 (1992): 339-350. In agreement with Manes (p. 340, footnote 4), our culture has given domesticated animals such as pets, the status of quasi-subjects because there is a sense that they can communicate with us. Also refer to Berta E. Perez, “Midwesterners' Perceptions of and Attitudes towards Pets," Central Issues in Anthropology, no. 2 (1986): 13-24, and "Pets: The Epitome of Neoteny in Biology and Culture," which has been accepted for publication. She posits that pets are endowed with quasi-human qualities, including the privilege to communicate with us. Pets are neither animals, nor humans; they are somewhere in between or ambiguous beings that are quasi-human and quasi-animal; and metaphorically, they are perceived, made, and treated to be permanent "young children."

${ }^{34}$ Susan Sperling, Animal Liberators. Research and Morality, p 10.

${ }^{35}$ See Christopher Manes, "Nature and Silence," pp. 339 340. In this article Manes discusses the issue that only humans in our culture and in most literate societies, have the status as speaking subjects as opposed to nature (animals, plants, and inert entities-rivers and stones). He also makes the distinction between privileged human speakers versus silenced human speakers such as women, minorities, children, prisoners, and the insane, who are considered vis-à-vis nature.

${ }^{36}$ Personal communication, 17 December 1986.

${ }^{37}$ Michael W. Fox, Returning to Eden. Animal Rights and Human Responsibility, pp. 216-217.

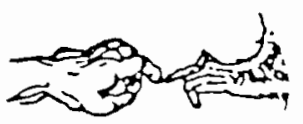

